\title{
Whole Genome Grey and White matter DNA Methylation Profiles in Dorsolateral Prefrontal cortex
}

Jose Vicente Sanchez-Mut ${ }^{1}$, Holger Heyn ${ }^{2}$, Enrique Vidal ${ }^{3}$, Raúl Delgado-Morales ${ }^{4,5}$, Sebastian Moran ${ }^{4}$, Sergi Sayols ${ }^{6}$, Juan Sandoval ${ }^{7}$, Isidre Ferrer ${ }^{8}$, Manel Esteller ${ }^{4^{*}}$ and Johannes Gräff ${ }^{*}$

${ }^{1}$ Brain Mind Institute, Faculty of Life Sciences, Ecole Polytechnique Fédérale de Lausanne, $\mathrm{CH}$ 1015 Lausanne, Switzerland

${ }^{2}$ Single Cell Genomics Unit, Centre Nacional d'Anàlisi Genòmica, E-08028 Barcelona, Catalonia, Spain.

${ }^{3}$ Centre for Genomic Regulation (CRG), The Barcelona Institute of Science and Technology, Barcelona E-08003, Spain; Universitat Pompeu Fabra (UPF), Barcelona, Spain.

${ }^{4}$ Cancer Epigenetics Group, Cancer Epigenetics and Biology Program, Institut d'Investigació Biomedica de Bellvitge, E-08908 Barcelona, Spain.

${ }^{5}$ Department of Psychiatry and Neuropsychology, School for Mental Health and Neuroscience (MHeNS), Maastricht University, Universiteitssingel 50, 6200 MD, Maastricht, The Netherlands.

${ }^{6}$ Bioinformatics Core Facility, Institute of Molecular Biology, D-55128 Mainz, Germany.

${ }^{7}$ Biomarkers and Precision Medicine Unit, Health Research Institute La Fe, Valencia 46026, Spain.

${ }^{8}$ Institute of Neuropathology, Bellvitge University Hospital, University of Barcelona, Centre for Biomedical Research on Neurodegenerative Diseases (CIBERNED), E-08908 Hospitalet de Llobregat, Spain.

(

${ }^{*}$ Equal contribution

Running title: Grey and White matter methylomes

To whom correspondence should be addressed:

Johannes Gräff, École Polytechnique Fédérale de Lausanne (EPFL), Sciences de la vie (SV), Brain Mind Instute (BMI), Station 19, CH-1015 Lausanne, Switzerland. Tel : +41216930713.

Fax : +41216930955 johannes.graeff@epfl.ch

Manel Esteller, Programa d'Epigenètica i Biologia del Càncer (PEBC), Fundació Institut d'Investigació Biomèdica de Bellvitge (IDIBELL), Av. Gran Via de l'Hospitalet, 199-203, E-08908 L'Hospitalet del Llobregat (Barcelona), Spain. Tel: +34 9326071 21. Fax : +34 932607219. mesteller@idibell.cat

Keywords: DNA methylation, Alzheimer's disease, Parkinson's disease, Multiple sclerosis, Amyotrophic lateral sclerosis

This article has been accepted for publication and undergone full peer review but has not been through the copyediting, typesetting, pagination and proofreading process which may lead to differences between this version and the Version of Record. Please cite this article as an 'Accepted Article', doi: 10.1002/syn.21959

(C) 2017 Wiley Periodicals, Inc.

Received: Sep 30, 2016; Revised: Jan 10, 2017; Accepted: Jan 11, 2017

This article is protected by copyright. All rights reserved. 


\section{Abstract}

The brain's neocortex is anatomically organized into grey and white matter, which are mainly composed by neuronal and glial cells, respectively. The neocortex can be further divided in different Brodmann areas according to their cytoarchitectural organization, which are associated with distinct cortical functions. There is increasing evidence that brain development and function are governed by epigenetic processes, yet their contribution to the functional organization of the neocortex remains incompletely understood. Herein, we determined the DNA methylation patterns of grey and white matter of dorsolateral prefrontal cortex (Brodmann area 9), an important region for higher cognitive skills that is particularly affected in various neurological diseases. For avoiding inter-individual differences, we analyzed white and grey matter from the same donor using whole genome bisulfite sequencing, and for validating their biological significance, we used Infinium HumanMethylation450 BeadChip and pyrosequencing in ten and twenty independent samples respectively. The combination of these analysis indicated robust grey-white matter differences in DNA methylation. What is more, cell type-specific markers were enriched among the most differentially methylated genes. Interestingly, we also found an outstanding number of grey-white matter differentially methylated genes that have previously been associated with Alzheimer's, Parkinson's, and Huntington's disease, as well as Multiple and Amyotrophic lateral sclerosis. The data presented here thus constitute an important resource for future studies not only to gain insight into brain regional as well as grey and white matter differences, but also to unmask epigenetic alterations that might underlie neurological and neurodegenerative diseases.

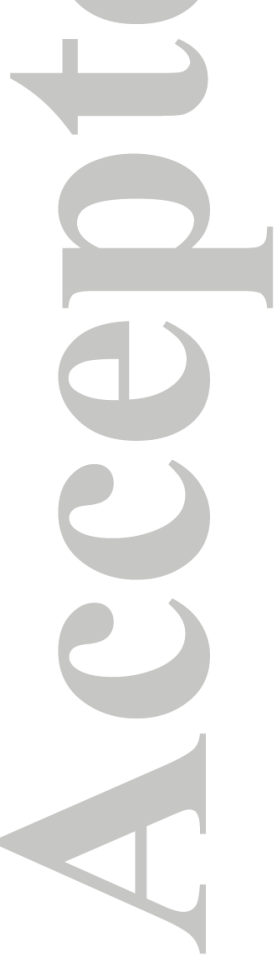




\section{Introduction}

The neocortex is the largest structure in the human brain representing $82 \%$ of total brain mass and containing more than 80 billion cells. It is the brain region where cognition, language and complex behaviors take place and are being planned, and where neurons and glial cells form a patterned structure that defines the two main divisions of the brain: the grey and the white matter. The grey matter, the greyish appearance of which is the consequence of the presence of cell bodies, is mainly composed by neurons and glial cells (glia/neuron ratio $\sim 1.5$ ) whereas the white matter, the whiteness of which is due to the myelin that covers axons, is mostly composed by glial cells (glia/neuron ratio 15.5) (Azevedo et al., 2009). Therefore, unraveling the epigenetic profiles governing grey and white matter will provide information about the epigenetic landscapes of neurons and glial cells. This quest has recently started to be addressed using genome-wide (Guintivano et al., 2013; Iwamoto et al., 2011; Kessler et al., 2016; Kozlenkov et al., 2014; Labonte et al., 2013) and whole-genome approaches (Lister et al., 2013). In these studies, immunolabeled neuron and glial cells were isolated and their DNA methylation patterns examined allowing for the comparison of pure populations of cellular types, yet without considering their spatial organization. This is an important handicap because several studies have highlighted the importance of considering anatomical compartments. Indeed, neuron and glial cells show specific spatial profiles of gene expression according to their emplacement within anatomical structures (Bohland et al., 2010; Ko et al., 2013), which is also evident by characteristic DNA methylation profiles indicating an important spatial regulation as shown in other brain areas (Davies et al., 2012; Hernandez et al., 2011; Kozlenkov et al., 2016; Ladd-Acosta et al., 2007; Lee et al., 2011; Sanchez-Mut et al., 2013; Xin et al., 2010).

In order to consider the spatial regulation of cerebral cortex and to discern the DNA methylation profiles of grey and white matter, we focused on dorsolateral prefrontal cortex Brodmann area 9 (BA9) because it is involved in higher cognitive skills such as memory and cognition (Wood and Grafman, 2003), and because it is also frequently altered in neurological diseases, including Alzheimer's disease (AD) (Dournaud et al., 1995; Grouselle et al., 1998; Igarashi et al., 2011), Parkinson's disease (PD) (Dumitriu et al., 2012; Lanoue et al., 2013; Lanoue et al., 2010), Huntington's disease (HD) (Hoss et al., 2015; Labadorf et al., 2015; Mina et al., 2016), as well as mood and bipolar disorders (Brooks et al., 2010; Fitzgerald et al., 2006; Whitfield et al., 2015). We performed a whole genome bisulfite sequencing analysis (WGBS) of grey and white matter providing a comprehensive catalogue of DNA methylation profiles at base-pair resolution. In order to avoid inter-individual variability, we acutely dissected donor-matched grey and white matter from postmortem samples. Importantly, we validated the biological significance of these findings using an independent cohort of prefrontal cortex samples by Infinium $450 \mathrm{~K}$ array and pyrosequencing.

\section{Methods}

This article is protected by copyright. All rights reserved. 
Human samples - Post-mortem tissues were obtained from the Institute of Neuropathology Brain Bank (HUB-ICO-IDIBELL Biobank) following the practices and expertise of BrainNet Europe Bank (http://www.brainnet-europe.org/) "Network of Excellence" funded by the European Commission in the 6th Framework Program "Life Science" (LSHM-CT-2004-503039). All samples were obtained in agreement with ethical issues and legislations defined by the European Union and after the approval of the local Ethic Committee. DNA was extracted from grey and white matter of dorsolateral prefrontal cortex (Brodmann area 9). The EZ DNA methylation kit (Zymo Research) was used for bisulphite concersion of all DNA samples used as previously described (Bibikova et al., 2011).

Previously reported WGBS gray and white matter data from the same control donor were used (GSE47966 GSM1173772 - Grey matter - (Lister et al., 2013); GSM1279516 GSE52271white matter - (Sanchez-Mut et al., 2016); female 64 years old). Five additional control grey and white matter were hybridized on $450 \mathrm{~K}$ arrays (three females and two male aged $69.4 \pm 4.3$ and four females and one male aged $64.4 \pm 9.7$ respectively). A third set of ten control grey and ten white matter samples was used for pyrosequencing validation (seven females and three male aged $70.3 \pm 3.8$ and eight females and two male aged $69.1 \pm 5.1$ respectively).

Pyrosequencing - The set of primers for PCR amplification and sequencing (Supplementary table 1) were designed using the software PyroMark assay design version 2.0.01.15 (Qiagen); amplification primers hybridize with CpG-free sites to ensure methylation-independent reaction and one primer (opposite to the sequencing primer) is biotinylated to convert the PCR product to single-stranded DNA templates. We used $1 \mathrm{ul}$ of bisulphite-treated DNA for each PCR. We used (Bibikova et al., 2011)the Vacuum Prep Tool (Quiagen) to prepare single-stranded PCR products according to manufacturer's instructions. Pyrosequencing reactions and methylation quantification were performed in a PyroMark Q24 System version 2.0.6 (Qiagen).

Whole-genome bisulfite sequencing data processing - Sequence alignment and methylation calling were performed with version 0.7.4 of Bismark software (Krueger and Andrews, 2011). We used hg19 as reference genome and retrieved genomic information from Biomart (Haider et al., 2009). SAM/BAM and BED files handling was done using SAMtools (Li et al., 2009), bedtools (Quinlan and Hall, 2010) and Tabix (Li, 2010). Statistical analysis and graphic representation was performed with $\mathrm{R}$ (http://www.R-project.org) and libraries multicore and ggplot2. We defined the promoter region as $2 \mathrm{~kb}$ flanking the transcription start site (TSS). TSS was considered to be the upstream-most base of all the transcripts of the gene. Smoothed methylation profiles were generated following the BSmooth pipeline (Hansen et al., 2012).

CpG distance correlation - We assessed distance correlation of $\mathrm{CpG}$ in close proximity gathering information about methylation and relative distance up to 2000 bases away from all $\mathrm{CpG}$ sites and correlating pair-wise methylation at single $\mathrm{CpG}$ sites for each relative distance. 
Detection of differentially methylated regions - Differentially methylated regions (DMR) were identified as regions with more than 5 consecutive CpG sites that showed a consistent difference between the $95 \% \mathrm{Cl}$ of the smoothed methylation profile (Hansen et al., 2012).

Detection of histone marks - We obtained human histone marks for human adult brain inferior temporal lobe available at the ENCODE project (GSE17312) and CCAT peak caller(Xu et al., 2010) with the standard parameter for histone marks.

Microarray-based DNA methylation analysis with Infinium 450k array - The Infinium methylation assay was carried out as described previously (Bibikova et al., 2011). P-values for probes covering and following consistent tendencies with the identified DMRs were obtained using Kruskal-Wallis test and false discovery rate (FDR<0.05) adjustment for multiple comparisons.

RNA expression profiling - RNA expression profiling was performed following the Pico Profiling method(Gonzalez-Roca et al., 2010). Each sample analyzed by WGBS was also hybridized to a Human Gene ST 1.0 Arrays (Affymetrix). The arrays were scanned in a GeneChip Scanner 3000 (Affymetrix). CEL files were generated from DAT files using GCOS software (Affymetrix). To generate the $\log 2$ expression estimates, overall array intensity was normalized between arrays and the probe intensity of all probes in a probeset summarized to a single value using RMA (Robust Multichip Average) algorithm(Irizarry et al., 2003).

Disease-associated genes - AD-associated genes were obtained from AlzGene database (Bertram et al., 2007), PD-associated genes from PDGene (Lill et al., 2012), Amyotrophic lateral sclerosis-associated genes from ALSGene (Lill et al., 2011), and Multiple Sclerosis- associated genes from MSGene (Lill CM, 2012). Relative gene amounts was assayed using two-tailed Fisher's exact test and the level of significance (alpha) set at $p<0.05$.

\section{Results}

\section{WGBS patterns}

We performed WGBS of grey and white matter from BA9 obtained from the same patient in order to avoid inter-individual variability. $19 \times 10^{7}$ paired-end reads corresponding to a global coverage of $\sim 10 x$ sequencing depth and interrogating $\sim 94 \%$ of genome were successfully mapped and obtained for both samples. Closer inspection indicated that more than $10^{9}$ single Cs $(98 \%)$ were covered in both samples with $3.8 \times 10^{8}(6,2 \%)$ and $3.2 \times 10^{8}(5,2 \%)$ of reads methylated in grey and white matter respectively. In detail, $27.4 \times 10^{7}(79,3 \%)$ of CGs, $8.6 \times 10^{7}$ $(3,8 \%)$ of CAs, $2.8 \times 10^{7}(1,3 \%)$ of CTs and $0.7 \times 10^{7}(0,5 \%)$ of CCs reads were methylated in grey matter whereas $28.5 \times 10^{7}$ of CGs $(78,9 \%), 3.5 \times 10^{7}(1,5 \%)$ of CAs, $1.1 \times 10^{7}(0,5 \%)$ of CTs and $0.6 \times 10^{7}(0,3 \%)$ of CCs were methylated in white matter. Thus, we observed higher levels of nonCG methylation in grey matter $(30,8 \%$ vs. $15,3 \%$ of total C methylated reads were in non-CG context) while CG methylation was similar in both samples $(79,3 \%$ vs. $78,9 \%)$. Noticeably, 
similar results were obtained in immunolabeled neuronal and gial cells suggesting that this pattern represents a general tendency in the brain (Lister et al., 2013).

Next, we asked how methylation values were distributed. As expected, we observed a similar bimodal distribution of CG methylation in both samples with $\sim 88 \%$ of $\mathrm{Cs}$ methylated $(>66 \%$ average methylation value) and $\sim 5 \%$ of $\mathrm{Cs}$ unmethylated ( $<33 \%$ average methylation value). On the contrary, non-CG methylation showed a single distribution with most of Cs being unmethylated ( $\sim 90 \%$ of total Cs with average methylation value lower than $33 \%$ ) even in grey matter where overall methylation levels were higher (Supplementary figure 1).

In keeping with previous results (Heyn et al., 2012), we observed a significant correlation between neighboring CG methylation site levels (Supplementary figure 2). On the contrary, no correlation was observed for non-CG methylation. This might be explained by the fact that CG methylation shows a bimodal distribution and tends to form clusters whereas non-CG methylation tends to be more scattered (Hebestreit et al., 2013; Lister et al., 2013).

Next, we assessed the relation between CG and non-CG methylation. To solve the problem of the scattered pattern of non-CG methylation, we defined flanking windows of $500 \mathrm{bp}$ and $2 \mathrm{~kb}$ around the $\mathrm{CpG}$ islands and interrogated the non-CG methylation in the neighborhoods of CG methylated and unmethylated islands. Interestingly, CG and non-CG methylation were correlated in grey and white matter samples with the former showing higher correlation values (Supplementary Figure 3; $R=0.51 \mathrm{p}$-val<0.001 and $\mathrm{R}=0.21 \mathrm{p}$-val<0.001; Pearson correlation values for $500 \mathrm{bp}$ and $2 \mathrm{~kb}$ windows respectively). In keeping with previous results(Guo et al., 2014; Kulis et al., 2015; Sun et al., 2016; Ziller et al., 2011), we observed a correlation between CG and non-CG methylation which was stronger in grey matter where neurons, with higher levels of non-CG methylation, are more abundant (Guo et al., 2014; Lister et al., 2013; Sun et al., 2016).

Considering all of the aforementioned, we then decided to focus all subsequent analyses on CG methylation for the following reasons: 1) The functional relevance of CG methylation in gene regulation has been unequivocally demonstrated (Vinson and Chatterjee, 2012); 2) the correlation between neighboring CG methylation site levels allows the use of smoothing algorithms increasing the power, accuracy and sensitivity to detect differentially methylated regions (DMRs) (Hansen et al., 2012); 3) high-density array platforms are designed preferentially for interrogating CG methylation sites with the non-CG methylation probes being almost negligible; and 4) in contrast to the scattered pattern of non-CG methylation, differentially methylated CG loci can be precisely determined facilitating their validation using locus-specific techniques such as pyrosequencing.

\section{Differentially methylated regions}

To assess CG methylation in more detail, we used previously published smoothing methods (Hansen et al., 2012) and found 26914 DMRs between grey and white matter of BA9 (mean 
size $\sim 10^{2}-10^{3} \mathrm{bp}$; Figure $\left.1 \mathrm{~A}\right)$. These DMRs tend to lie on functional relevant regions as expected by the regulatory role of CG methylation (3,4 OR; Bootstrap pval<0.001). 6447 DMRs were located on promoters (4,1 OR; Bootstrap pval<0.001), 18900 on gene bodies (1,6 OR; Bootstrap pval<0.001), 6292 on enhancers (7,4 OR; Bootstrap pval<0.001), 1046 on TFBS $(7,1$ OR; Bootstrap pval<0.001) and 4689 on regions without regulatory function $(0,2$ OR; Bootstrap pval<0.001) (Figure 1B). Similar enrichment of differentially methylation regions in enhancer regions have been previously observed (Kozlenkov et al., 2014; Sun et al., 2016), supporting the accuracy of our results.

\section{Epigenetic crosstalk between DNA methylation and histone marks}

After that, we interrogated the relation between DNA methylation and histone marks using the comprehensive epigenetic profiling of human brain samples within the Roadmap project (Bernstein et al., 2010) because there is an important crosstalk between both epigenetic marks(Cedar and Bergman, 2009), in particular also for higher cognitive functions(Miller and Sweatt, 2006). As expected, H3K4me3 and H3K9ac, which are enriched on active promoters, tend to be non-methylated (Supplementary figure 4). In contrast, H3K9me3, a marker of heterochromatin, shows higher levels of DNA methylation. Furthermore, H3K36me3, which marks gene bodies of active genes, shows high levels of DNA methylation and H3K27ac, H3K4me1 and H3K27me3, which mark enhancers and polycomb genes, respectively, show intermediate DNA methylation levels. Noticeably, most of the DMR co-localized with euchromatin marks (H3K4me1, H3K4me3, H3K36me3, H3K27ac; 8,3 OR; Bootstrap pval<0.001) suggesting that the majority of DNA methylation differences between grey and white matter affect regulatory active regions whereas heterochromatin regions remain largely unaltered (H3K9me3; 0,3 OR.; Bootstrap pval<0.001): DMRs tend to lie on euchromatin regions 27,6 times more than on heterochromatin regions (Bootstrap pval<0.001). In detail, 8307 DMRs were located on H3K4me3 (12,7 OR; Bootstrap pval<0.001), 11959 on H3K27ac (7,9 OR; Bootstrap pval<0.001), 1739 on H3K27me3 (7,1 OR; Bootstrap pval<0.001), 7836 on H3K4me1 (5,8 OR; Bootstrap pval<0.001) and 2185 on H3K36me3 (2,6 OR; Bootstrap pval<0.001; Figure 1B). Supporting these results, we observed an important overlap between DNA sensitive sites in human brain samples (ENCODE/Duke University; Frontal cerebrum) and DMRs (23,1 OR; Bootstrap pval<0.001), which suggests that DMR tend to be located on open chromatin regions. Closer inspection revealed that 1045 DMRs were located on bivalent domains (H3K4me3+H3K27me3) (17,6 OR; Bootstrap pval<0.001) indicating that bivalent domains were the most overrepresented histone mark category of the genome.

\section{Correlation between DNA methylation and RNA expression}

In addition, we examined the correlation between DNA methylation and RNA values using GeneChip human gene 1.0ST array data (Supplementary table 2). In keeping with the idea that promoter DNA methylation represses RNA expression (Kelly et al., 2012), promoter DNA methylation was negatively correlated with gene expression (Figure 1C; Grey matter $R=-0.49$; 
White matter $\mathrm{R}=-0.47$; Pearson correlations, $\mathrm{p}$-val $<0.001$ ), supporting the biological significance of the observed DMRs. However, in contrast with previous observations (Zemach et al., 2010), no significant differences in RNA expression were observed in relation to gene body DNA methylation (data not shown).

\section{Validation of WGBS using 450K IIlumina Platform and pyrosequencing}

In order to validate WGBS results, we took advantage of the Infinium Human Methylation 450 BeadChip Kit which interrogates more than 485,000 methylation sites per sample at singlenucleotide resolution. DNA methylation profiles obtained from both platforms were highly correlated $\left(R^{2}=0.957\right.$ and $R^{2}=0.962$ for grey and white matter respectively). In detail, from 11860 DMRs identified by WGBS (Supplementary table 3), 4496 (38\%) were also covered by $450 \mathrm{~K}$ arrays and $3820(85 \%)$ of those were technically validated between both technologies (Supplementary figure 5). For further biological validation and for avoiding subject-specific differences, we used an additional five grey and five white matter samples. Importantly, 4010 of covered DMRs $(89,2 \%)$ showed consistent tendencies between independent samples (Supplementary figure 5) and 2806 (70 \%) significant differences (Supplementary table ; FDR<0.05) reinforcing the biological importance of these findings. As expected, a clustering analysis of $450 \mathrm{~K}$ CpGs covering DMRs showed a clear difference of DNA methylation between grey and white matter profiles in BA9 (Figure 2). Lastly, these data were also technically and biologically validated by pyrosequencing using a third set of ten grey and ten white matter samples. WGBS DMRs showing significant differences in the $450 \mathrm{~K}$ arrays were sorted according to their $\mathrm{CpG}$ mean differences and the top ranked genes were interrogated by pyrosequencing. These results revealed similar DNA methylation differences between grey and white matter in WGBS, 450K data, pyrosequencing and RNA expression (Table 1, supplementary table 4 , and supplementary figure 6 ).

\section{Enrichment of DMR on glial and neuronal genes}

Noticeably, we observed an important overlap of DMRs with promoters of neuronal (e.g., ENO2, TUBB3, MAP2 and MAPT) and glial genes (e.g., GFAP, GLUL, S100B and NOTCH1 for astrocytes and MBP, SOX10, MAG and MOG for oligodendrocytes: As expected, and in line with the negative correlation between promoter DNA methylation and gene expression, genes preferentially expressed in neurons were hypomethylated in grey matter whereas genes preferentially expressed in glial cells markers were hypomethylated in white matter (Figure 3A). Consistently, an outstanding number of genes differentially expressed genes between neurons, astrocytes, and oligodendrocytes (Cahoy et al., 2008) also shows differences in DNA methylation (Supplementary table 5).

Next, we compared our data with previously published and NCBI GEO accessible datasets investigating DNA methylation differences between neuron and glial cells. Our DMR list comprises more than $90 \%$ of genes covered by both platforms and differentially methylated in the $450 \mathrm{~K}$ dataset GSE41826 consisting of 29 neuron and glia paired prefrontal cortex samples 
(average DNA methylation between $\mathrm{NeuN}^{+}$and $\mathrm{NeuN}^{-}>5 \%$; FDR<0.05) (Guintivano et al., 2013). Besides, since human and mouse DNA methylation differences between neurons and glial cells are highly conserved(Kessler et al., 2016), we compared our DMR list with the WGBS dataset GSM11737786-91 consisting of three paired cortex murine samples (Lister et al., 2013) reanalyzed by Kessler et al(Kessler et al., 2016). Our DMR list includes more than $70 \%$ of genes differentially methylated in Kessler et al. data (Supplementary table 1 Kessler et al., 2016), supporting the reliability and functional relevance of our observations.

In addition, we explored the functional particularities of grey and white matter genes with DMRs in promoters using GeneCodis tool (Carmona-Saez et al., 2007; Nogales-Cadenas et al., 2009; Tabas-Madrid et al., 2012). Differentially methylated genes were enriched in Kyoto Encyclopedia of Genes and Genomes (KEGG) (Kanehisa and Goto, 2000) terms associated with neuron- and glia-specific processes such as regulation of actin cytoskeleton and axon guidance, Gap junctions, and Wnt signaling (Supplementary table 6). Similarly, Protein ANalysis THrough Evolutionary Relationships (PANTHER)(Thomas et al., 2003) terms such as synaptic vesicle trafficking, acetylcholine, oxytocine, GABA, and glutamate signaling genes were also enriched in DMRs between grey and white matter (Supplementary table 7). In this regard, these data are in line with the expected gene enrichments, presumably a direct consequence of the different composition of cells between grey (neuron-like) and white matter (glial-like). Interestingly, KEGG and PANTHER analysis also identified a significant enrichment of DMR in genes associated with $A D, P D$, and $H D$ as well as Amyotrophic lateral sclerosis (ALS) (Supplementary tables 6 and 7 ) indicating that an important fraction of differentially methylated genes between grey and white matter are associated with neurodegenerative diseases.

\section{Disease-associated genes differentially DNA methylated between grey and white matter}

To corroborate these observations, we next took advantage of the AlzGene (Bertram et al., 2007), PDGene(Lill et al., 2012), ALSGene(Lill et al., 2011), and MSGene(Lill CM, 2012) datasets, which constitute independent repositories of genes associated with AD, PD, ALS, and Multiple Sclerosis (MS), respectively. From the identified 6447 DMRs on promoters, 190 corresponded to previously AD-associated genes (5,97 O.R.; Fisher-test; pval<0.05), 314 to PD-associated genes (3.81 O.R.; Fisher-test; pval<0.05), 142 to Multiple Sclerosis-associated genes (7.38 O.R.; Fisher-test; pval<0.05), and 35 to Amyotrophic lateral sclerosis-associated genes (28.93 O.R.; Fisher-test; pval<0.05) (supplementary table 8). A closer inspection revealed interesting DNA methylation profiles regarding these genes. For instance, several important genes associated with AD, such as Clusterin (CLU) (Harold et al., 2009) and microtubule-associated protein tau (MAPT)(Grundke-lqbal et al., 1986), were hypomethylated in grey matter (Figure 3B). Similarly, genes associated with PD, such as Leucine-rich repeat kinase 2 (LRRK2)(Paisan-Ruiz et al., 2004) and PTEN Induced Putative Kinase 1 (PINK1) (Valente et al., 2004), were also hypomethylated in grey matter as well as Interleukin 1 Receptor Type 1 (IL1R1) (Schrijver et al., 1999) as well as TNF receptor superfamily member 
1A (TNFRSF1A) (Cereda et al., 2008), which are associated with MS and ALS respectively (Figure 3B).

\section{Discussion}

In this study, we used a novel approach to determine the specific characteristics of grey and white matter divisions in BA9. Acutely dissected grey and white matter from BA9 was isolated and its DNA extracted. WGBS and Human Infinium Human Methylation 450 BeadChip Kit arrays were used to determine their DNA methylation profiles and the resulting data was further validated by pyrosequencing.

Despite that WGBS can provide data on CG and non-CG methylation, we decided to focus on CG methylation for several practical regions. First, the effect of CG methylation on gene regulation has largely been demonstrated (Vinson and Chatterjee, 2012). Second, CG methylation of neighboring CG sites is strongly correlated facilitating the application of smoothing algorithms that increase the power and significance of the results (Hansen et al., 2012). Third, high-density array platforms interrogate mostly CG methylation facilitating the cross-validation between platforms (Sandoval et al., 2011). And finally, in contrast to the scattered pattern of non-CG methylation, loci of differentially CG methylation can be precisely determined facilitating the validation of the data using alternative techniques such as pyrosequencing.

Doing so, we found an important enrichment of DMRs in functionally relevant genome regions, especially in enhancers, which are, in turn, strongly associated with cell-type specificity (Creyghton et al., 2010; Zhu et al., 2013), consistent with previous reports (Kozlenkov et al., 2014; Sun et al., 2016). Similarly, our data show a significant negative correlation between promoter DNA methylation and gene expression, consistent with the idea that promoter DNA methylation represses RNA expression (Kelly et al., 2012). Finally, our results were also in agreement with the expected differences in cell type markers in grey and white matter as well as between grey and white matter-specific molecular pathways, supporting the biological significance of the observed DMRs.

To our knowledge, our study is the first to provide a complete and detailed landscape of DNA methylation profiles between the anatomically distinct grey and white matter. Previous studies interrogating DNA methylation profiles of neuron and glial cells have used isolated NeuNpositive cells and ChIP-on-chip assays (Iwamoto et al., 2011; Labonte et al., 2013). ChIP-onchip assays consist of immunoprecipitating DNA using antibodies that recognize $5 \mathrm{mC}$ or MBD proteins, a technique that is known to introduce a certain bias of sequence recognition and to be limited in resolution imposed by the array. Therefore, this technique can only represent a partial view of bona fide DNA methylation profiles. Others have used restriction enzyme-based methods (Kozlenkov et al., 2016; Montano et al., 2013; Sun et al., 2016) or Infinium HumanMethylation450 BeadChip arrays (Guintivano et al., 2013; Kozlenkov et al., 2014; Kozlenkov et al., 2016) that provide a broader representation of the genome but are biased to 
CpG-rich regions. Circumventing this problem, Lister and collaborators have recently reported a WGBS study on isolated NeuN cells (Lister et al., 2013), which is not biased by immunoprecipiation and which analyzes virtually all nucleotides of the genome in a comparable resolution to our data. Nonetheless, all these studies are based on NeuN-stained isolation of cells, which does not take the spatial information or the anatomical specialization between different brain regions into consideration. Yet, neuron and glial cells show characteristic spatial expression profiles according to specific anatomical structures (Bohland et al., 2010; Ko et al., 2013) which are also reflected at DNA methylation profiles (Davies et al., 2012; Hernandez et al., 2011; Ladd-Acosta et al., 2007; Lee et al., 2011; Sanchez-Mut et al., 2013; Xin et al., 2010).

Notwithstanding, our approach might be limited by imperfections in dissection and the impurity of the grey and white matter divisions and the limited number of samples analyzed. Furthermore, standard bisulfite conversion cannot recognize hydroxymethylation (Huang et al., 2010), an emerging epigenetic modification in the brain with various functions including cognition (Massart et al., 2014; Mellen et al., 2012), nor can we capture the highly dynamic nature of DNA methylation, including DNA methylation changes associated with learning and memory (Graff and Mansuy, 2008; Lubin et al., 2011; Miller and Sweatt, 2006; Numata et al., 2012).

Interestingly, our analysis has revealed an outstanding enrichment of DMR in genes associated with several neurological and neurodegenerative diseases. In particular, we have observed an enrichment of DMRs in genes previously associated with AD, PD, HD, MS and ALS. AD- and PD-related genes such as CLU and MAPT, and LRRK2 and PINK1 are differentially methylated between grey and white matter, as well as IL1R1 and TNFRSF1A, which are associated with MS and ALS respectively. In line with the repressive effect of promoter DNA methylation, these genes tend to be hypermethylated (Figure 3B) and less expressed (Supplementary table 2) in white matter, where a higher proportion of glial cells are observed. In follow-up studies, it will be interesting to determine whether these genes are differentially methylated in brain regions particularly affected in neurodegenerative diseases. First attempts along this line, exemplified by MAPT DNA methylation, have shown a complex scenario in which the specific brain region DNA methylation patterns can be influenced by the genetic background and the disease status (Coupland et al., 2014).

These observations indicate that genes associated with neurodegenerative diseases are differentially regulated between grey and white matter, which are in turn differentially affected in such diseases, reinforcing the necessity of considering the cellular and spatial compartmentalization in neurodegenerative studies. In addition, these data also suggest that such genes play a major role in grey matter and, by extension, in neurons, while other genes showing the opposite relation might need to be interpreted as glia-relevant genes. Also, since neurodegenerative diseases are primarily affecting particular cell types and specific brain regions, an alteration of the cellular ratios and spatial distribution of their specific epigenetic patterns are expected. As a consequence, a direct comparison between control and disease- 
affected tissues should not only result in alterations underlying neurodegeneration diseases but also in differences between cell patterns, that can be present even in studies based on neuron/glia fluorescence-activated cell sorting (FACS), where a minimal contamination of cells cannot be completely discarded. Therefore, previous studies investigating changes in DNA methylation in neurodegeneration in genes showing differences between grey and white matter, or neuron and glial cells, ought to be carefully interpreted in light of our observations presented here (for a detailed revision of genes previously associated with $A D$ see (Sanchez-Mut and Graff, 2015), PD see (Feng et al., 2015), MS see (Li et al., 2016), and ALS see(Paez-Colasante et al., 2015)).

Taken together, the results presented here offer a complete and detailed landscape of DNA methylation profiles of grey and white matter in BA9 that constitutes an important resource to assist future studies determining cell type-specific (epigenetic) differences pertinent (or not) to this region of the cortex. Additionally, our data may also be relevant to unmask and better understand epigenetic alterations underlying neurological and neurodegenerative diseases, and to assist case-control studies where cell type compositions are not considered.

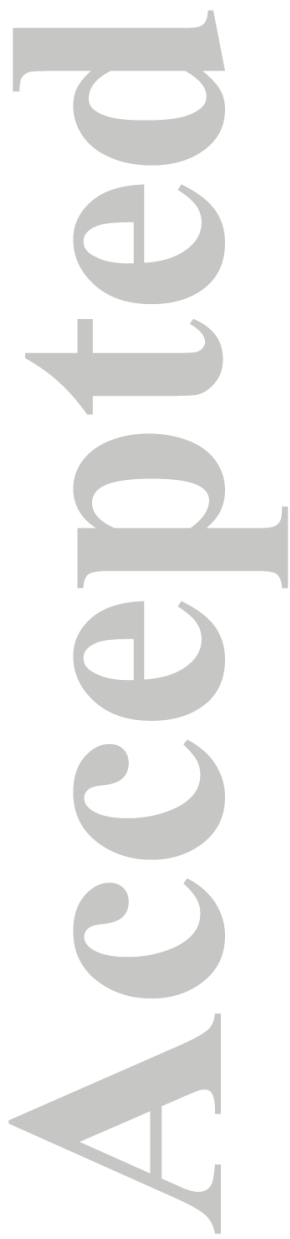




\section{Acknowledgments}

This work was supported by the European Research Council (ERC-2015-StG 678832), by the Swiss National Science Foundation, the National Competence Center for Research SYNAPSY, the SYNAPSIS Foundation, the Béatrice Ederer-Weber Stiftung, the Floshield Foundation, and the Alzheimer's Association (NIRG-15-363964). HH is a Miguel Servet (CP14/00229) researcher funded by the Spanish Institute of Health Carlos III (ISCIII). ME is an ICREA Research Professor. JG is an MQ fellow and a NARSAD Independent Investigator.

\section{Author contributions}

JVSM, HH, IF, ME, and JG conceived the idea of this project. JVSM, and HH performed the experiments. EV, SM, SS, IF, JS, and RDM contributed to the analysis of the data. JVSM, ME, and JG wrote the manuscript with inputs from all the other authors.

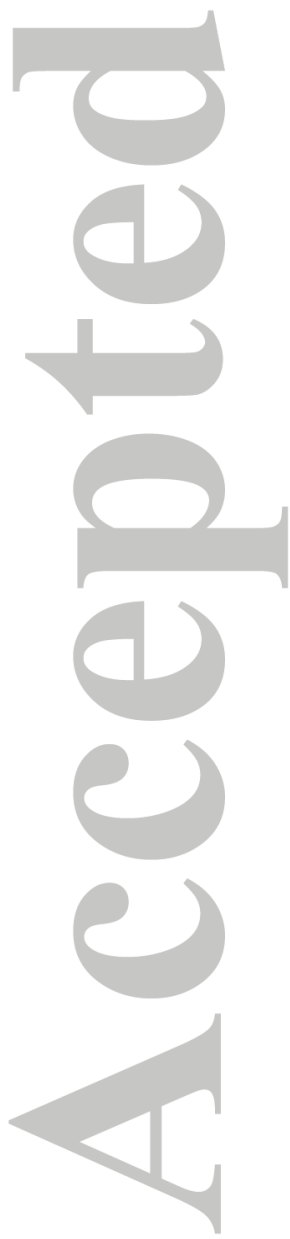




\section{References}

Azevedo FA, Carvalho LR, Grinberg LT, Farfel JM, Ferretti RE, Leite RE, Jacob Filho W, Lent R, Herculano-Houzel S. 2009. Equal numbers of neuronal and nonneuronal cells make the human brain an isometrically scaled-up primate brain. The Journal of comparative neurology 513(5):532-541.

Bertram L, McQueen MB, Mullin K, Blacker D, Tanzi RE. 2007. Systematic meta-analyses of Alzheimer disease genetic association studies: the AlzGene database. Nature genetics 39(1):17-23.

Bibikova M, Barnes B, Tsan C, Ho V, Klotzle B, Le JM, Delano D, Zhang L, Schroth GP, Gunderson KL, Fan JB, Shen R. 2011. High density DNA methylation array with single CpG site resolution. Genomics 98(4):288-295.

Bohland JW, Bokil H, Pathak SD, Lee CK, Ng L, Lau C, Kuan C, Hawrylycz M, Mitra PP. 2010. Clustering of spatial gene expression patterns in the mouse brain and comparison with classical neuroanatomy. Methods 50(2):105-112.

Brooks JO, 3rd, Bearden CE, Hoblyn JC, Woodard SA, Ketter TA. 2010. Prefrontal and paralimbic metabolic dysregulation related to sustained attention in euthymic older adults with bipolar disorder. Bipolar disorders 12(8):866-874.

Cahoy JD, Emery B, Kaushal A, Foo LC, Zamanian JL, Christopherson KS, Xing Y, Lubischer JL, Krieg PA, Krupenko SA, Thompson WJ, Barres BA. 2008. A transcriptome database for astrocytes, neurons, and oligodendrocytes: a new resource for understanding brain development and function. The Journal of neuroscience : the official journal of the Society for Neuroscience 28(1):264-278.

Carmona-Saez P, Chagoyen M, Tirado F, Carazo JM, Pascual-Montano A. 2007. GENECODIS: a web-based tool for finding significant concurrent annotations in gene lists. Genome biology 8(1):R3.

Cedar H, Bergman Y. 2009. Linking DNA methylation and histone modification: patterns and paradigms. Nature reviews Genetics 10(5):295-304.

Cereda C, Baiocchi C, Bongioanni P, Cova E, Guareschi S, Metelli MR, Rossi B, Sbalsi I, Cuccia MC, Ceroni M. 2008. TNF and sTNFR1/2 plasma levels in ALS patients. Journal of neuroimmunology 194(1-2):123-131.

Coupland KG, Mellick GD, Silburn PA, Mather K, Armstrong NJ, Sachdev PS, Brodaty H, Huang Y, Halliday GM, Hallupp M, Kim WS, Dobson-Stone C, Kwok JB. 2014. DNA methylation of the MAPT gene in Parkinson's disease cohorts and modulation by vitamin $E$ in vitro. Movement disorders : official journal of the Movement Disorder Society 29(13):16061614.

Creyghton MP, Cheng AW, Welstead GG, Kooistra T, Carey BW, Steine EJ, Hanna J, Lodato MA, Frampton GM, Sharp PA, Boyer LA, Young RA, Jaenisch R. 2010. Histone H3K27ac separates active from poised enhancers and predicts developmental state. Proceedings of the National Academy of Sciences of the United States of America 107(50):21931-21936.

Davies MN, Volta M, Pidsley R, Lunnon K, Dixit A, Lovestone S, Coarfa C, Harris RA, Milosavljevic A, Troakes C, Al-Sarraj S, Dobson R, Schalkwyk LC, Mill J. 2012. Functional annotation of the human brain methylome identifies tissue-specific epigenetic variation across brain and blood. Genome biology 13(6):R43.

Dournaud P, Delaere P, Hauw JJ, Epelbaum J. 1995. Differential correlation between neurochemical deficits, neuropathology, and cognitive status in Alzheimer's disease. Neurobiology of aging 16(5):817-823.

Dumitriu A, Latourelle JC, Hadzi TC, Pankratz N, Garza D, Miller JP, Vance JM, Foroud T, Beach TG, Myers RH. 2012. Gene expression profiles in Parkinson disease prefrontal cortex implicate FOXO1 and genes under its transcriptional regulation. PLoS genetics 8(6):e1002794. 
Feng Y, Jankovic J, Wu YC. 2015. Epigenetic mechanisms in Parkinson's disease. Journal of the neurological sciences 349(1-2):3-9.

Fitzgerald PB, Oxley TJ, Laird AR, Kulkarni J, Egan GF, Daskalakis ZJ. 2006. An analysis of functional neuroimaging studies of dorsolateral prefrontal cortical activity in depression. Psychiatry research 148(1):33-45.

Gonzalez-Roca E, Garcia-Albeniz X, Rodriguez-Mulero S, Gomis RR, Kornacker K, Auer H. 2010. Accurate expression profiling of very small cell populations. PloS one 5(12):e14418.

Graff J, Mansuy IM. 2008. Epigenetic codes in cognition and behaviour. Behavioural brain research 192(1):70-87.

Grouselle D, Winsky-Sommerer R, David JP, Delacourte A, Dournaud P, Epelbaum J. 1998. Loss of somatostatin-like immunoreactivity in the frontal cortex of Alzheimer patients carrying the apolipoprotein epsilon 4 allele. Neuroscience letters 255(1):21-24.

Grundke-Iqbal I, Iqbal K, Quinlan M, Tung YC, Zaidi MS, Wisniewski HM. 1986. Microtubuleassociated protein tau. A component of Alzheimer paired helical filaments. The Journal of biological chemistry 261(13):6084-6089.

Guintivano J, Aryee MJ, Kaminsky ZA. 2013. A cell epigenotype specific model for the correction of brain cellular heterogeneity bias and its application to age, brain region and major depression. Epigenetics 8(3):290-302.

Guo JU, Su Y, Shin JH, Shin J, Li H, Xie B, Zhong C, Hu S, Le T, Fan G, Zhu H, Chang Q, Gao Y, Ming GL, Song H. 2014. Distribution, recognition and regulation of non-CpG methylation in the adult mammalian brain. Nature neuroscience 17(2):215-222.

Haider S, Ballester B, Smedley D, Zhang J, Rice P, Kasprzyk A. 2009. BioMart Central Portal--

unified access to biological data. Nucleic acids research 37(Web Server issue):W23-27.
Hansen KD, Langmead B, Irizarry RA. 2012. BSmooth: from whole genome bisulfite sequencing reads to differentially methylated regions. Genome biology 13(10):R83.

Harold D, Abraham R, Hollingworth P, Sims R, Gerrish A, Hamshere ML, Pahwa JS, Moskvina V, Dowzell K, Williams A, Jones N, Thomas C, Stretton A, Morgan AR, Lovestone S, Powell J, Proitsi P, Lupton MK, Brayne C, Rubinsztein DC, Gill M, Lawlor B, Lynch A, Morgan K, Brown KS, Passmore PA, Craig D, McGuinness B, Todd S, Holmes C, Mann D, Smith AD, Love S, Kehoe PG, Hardy J, Mead S, Fox N, Rossor M, Collinge J, Maier W, Jessen F, Schurmann B, Heun R, van den Bussche H, Heuser I, Kornhuber J, Wiltfang J, Dichgans M, Frolich L, Hampel H, Hull M, Rujescu D, Goate AM, Kauwe JS, Cruchaga C, Nowotny P, Morris JC, Mayo K, Sleegers K, Bettens K, Engelborghs S, De Deyn PP, Van Broeckhoven C, Livingston G, Bass NJ, Gurling H, McQuillin A, Gwilliam R, Deloukas $P$, Al-Chalabi A, Shaw CE, Tsolaki M, Singleton AB, Guerreiro R, Muhleisen TW, Nothen MM, Moebus S, Jockel KH, Klopp N, Wichmann HE, Carrasquillo MM, Pankratz VS, Younkin SG, Holmans PA, O'Donovan M, Owen MJ, Williams J. 2009. Genome-wide association study identifies variants at CLU and PICALM associated with Alzheimer's disease. Nature genetics 41(10):1088-1093.

Hebestreit K, Dugas M, Klein HU. 2013. Detection of significantly differentially methylated regions in targeted bisulfite sequencing data. Bioinformatics 29(13):1647-1653.

Hernandez DG, Nalls MA, Gibbs JR, Arepalli S, van der Brug M, Chong S, Moore M, Longo DL, Cookson MR, Traynor BJ, Singleton AB. 2011. Distinct DNA methylation changes highly correlated with chronological age in the human brain. Human molecular genetics 20(6):1164-1172.

Heyn H, Li N, Ferreira HJ, Moran S, Pisano DG, Gomez A, Diez J, Sanchez-Mut JV, Setien F, Carmona FJ, Puca AA, Sayols S, Pujana MA, Serra-Musach J, Iglesias-Platas I, Formiga F, Fernandez AF, Fraga MF, Heath SC, Valencia A, Gut IG, Wang J, Esteller M. 2012. Distinct DNA methylomes of newborns and centenarians. Proceedings of the National Academy of Sciences of the United States of America 109(26):10522-10527.

Hoss AG, Labadorf A, Latourelle JC, Kartha VK, Hadzi TC, Gusella JF, MacDonald ME, Chen JF, Akbarian S, Weng Z, Vonsattel JP, Myers RH. 2015. miR-10b-5p expression in 
Huntington's disease brain relates to age of onset and the extent of striatal involvement. BMC medical genomics 8:10.

Huang Y, Pastor WA, Shen Y, Tahiliani M, Liu DR, Rao A. 2010. The behaviour of 5hydroxymethylcytosine in bisulfite sequencing. PloS one 5(1):e8888.

Igarashi M, Ma K, Gao F, Kim HW, Rapoport SI, Rao JS. 2011. Disturbed choline plasmalogen and phospholipid fatty acid concentrations in Alzheimer's disease prefrontal cortex. Journal of Alzheimer's disease : JAD 24(3):507-517.

Irizarry RA, Bolstad BM, Collin F, Cope LM, Hobbs B, Speed TP. 2003. Summaries of Affymetrix GeneChip probe level data. Nucleic acids research 31(4):e15.

Iwamoto K, Bundo M, Ueda J, Oldham MC, Ukai W, Hashimoto E, Saito T, Geschwind DH, Kato T. 2011. Neurons show distinctive DNA methylation profile and higher interindividual variations compared with non-neurons. Genome research 21(5):688-696.

Kanehisa M, Goto S. 2000. KEGG: kyoto encyclopedia of genes and genomes. Nucleic acids research 28(1):27-30.

Kelly TK, Liu Y, Lay FD, Liang G, Berman BP, Jones PA. 2012. Genome-wide mapping of nucleosome positioning and DNA methylation within individual DNA molecules. Genome research 22(12):2497-2506.

Kessler NJ, Van Baak TE, Baker MS, Laritsky E, Coarfa C, Waterland RA. 2016. CpG methylation differences between neurons and glia are highly conserved from mouse to human. Human molecular genetics 25(2):223-232.

Ko Y, Ament SA, Eddy JA, Caballero J, Earls JC, Hood L, Price ND. 2013. Cell type-specific genes show striking and distinct patterns of spatial expression in the mouse brain. Proceedings of the National Academy of Sciences of the United States of America 110(8):3095-3100.

Kozlenkov A, Roussos P, Timashpolsky A, Barbu M, Rudchenko S, Bibikova M, Klotzle B, Byne W, Lyddon R, Di Narzo AF, Hurd YL, Koonin EV, Dracheva S. 2014. Differences in DNA methylation between human neuronal and glial cells are concentrated in enhancers and non-CpG sites. Nucleic acids research 42(1):109-127.

Kozlenkov A, Wang $M$, Roussos $P$, Rudchenko $S$, Barbu M, Bibikova M, Klotzle B, Dwork AJ, Zhang B, Hurd YL, Koonin EV, Wegner M, Dracheva S. 2016. Substantial DNA methylation differences between two major neuronal subtypes in human brain. Nucleic acids research 44(6):2593-2612.

Krueger F, Andrews SR. 2011. Bismark: a flexible aligner and methylation caller for Bisulfite-Seq applications. Bioinformatics 27(11):1571-1572.

Kulis M, Merkel A, Heath S, Queiros AC, Schuyler RP, Castellano G, Beekman R, Raineri E, Esteve A, Clot G, Verdaguer-Dot N, Duran-Ferrer M, Russinol N, Vilarrasa-Blasi R, Ecker S, Pancaldi V, Rico D, Agueda L, Blanc J, Richardson D, Clarke L, Datta A, Pascual M, Agirre X, Prosper F, Alignani D, Paiva B, Caron G, Fest T, Muench MO, Fomin ME, Lee ST, Wiemels JL, Valencia A, Gut M, Flicek P, Stunnenberg HG, Siebert R, Kuppers R, Gut IG, Campo E, Martin-Subero Jl. 2015. Whole-genome fingerprint of the DNA methylome during human $B$ cell differentiation. Nature genetics 47(7):746-756.

Labadorf A, Hoss AG, Lagomarsino V, Latourelle JC, Hadzi TC, Bregu J, MacDonald ME, Gusella JF, Chen JF, Akbarian S, Weng Z, Myers RH. 2015. RNA Sequence Analysis of Human Huntington Disease Brain Reveals an Extensive Increase in Inflammatory and Developmental Gene Expression. PloS one 10(12):e0143563.

Labonte B, Suderman M, Maussion G, Lopez JP, Navarro-Sanchez L, Yerko V, Mechawar N, Szyf M, Meaney MJ, Turecki G. 2013. Genome-wide methylation changes in the brains of suicide completers. The American journal of psychiatry 170(5):511-520.

Ladd-Acosta C, Pevsner J, Sabunciyan S, Yolken RH, Webster MJ, Dinkins T, Callinan PA, Fan JB, Potash JB, Feinberg AP. 2007. DNA methylation signatures within the human brain. American journal of human genetics 81(6):1304-1315. 
Lanoue AC, Blatt GJ, Soghomonian JJ. 2013. Decreased parvalbumin mRNA expression in dorsolateral prefrontal cortex in Parkinson's disease. Brain research 1531:37-47.

Lanoue AC, Dumitriu A, Myers RH, Soghomonian JJ. 2010. Decreased glutamic acid decarboxylase mRNA expression in prefrontal cortex in Parkinson's disease. Experimental neurology 226(1):207-217.

Lee RS, Tamashiro KL, Aryee MJ, Murakami P, Seifuddin F, Herb B, Huo Y, Rongione M, Feinberg AP, Moran TH, Potash JB. 2011. Adaptation of the CHARM DNA methylation platform for the rat genome reveals novel brain region-specific differences. Epigenetics 6(11):1378-1390.

Li H. 2010. Tabix: fast retrieval of sequence features from generic TAB-delimited files. Bioninformatics(27):718-719.

Li X, Xiao B, Chen XS. 2016. DNA Methylation: a New Player in Multiple Sclerosis. Molecular neurobiology.

Lill CM, Abel O, Bertram L, Al-Chalabi A. 2011. Keeping up with genetic discoveries in amyotrophic lateral sclerosis: the ALSOD and ALSGene databases. Amyotrophic lateral sclerosis : official publication of the World Federation of Neurology Research Group on Motor Neuron Diseases 12(4):238-249.

Lill CM RJ, McQueen MB, Bagade S, Schjeide BM, Zipp F, Bertram L. 2012. The MSGene Database. Alzheimer Research Forum:Available at http://msgene.org.

Lill CM, Roehr JT, McQueen MB, Kavvoura FK, Bagade S, Schjeide BM, Schjeide LM, Meissner E, Zauft U, Allen NC, Liu T, Schilling M, Anderson KJ, Beecham G, Berg D, Biernacka JM, Brice A, DeStefano AL, Do CB, Eriksson N, Factor SA, Farrer MJ, Foroud T, Gasser T, Hamza T, Hardy JA, Heutink P, Hill-Burns EM, Klein C, Latourelle JC, Maraganore DM, Martin ER, Martinez M, Myers RH, Nalls MA, Pankratz N, Payami H, Satake W, Scott WK, Sharma M, Singleton AB, Stefansson K, Toda T, Tung JY, Vance J, Wood NW, Zabetian CP, andMe Genetic Epidemiology of Parkinson's Disease C, International Parkinson's Disease Genomics C, Parkinson's Disease GC, Wellcome Trust Case Control C, Young P, Tanzi RE, Khoury MJ, Zipp F, Lehrach H, Ioannidis JP, Bertram L. 2012. Comprehensive research synopsis and systematic meta-analyses in Parkinson's disease genetics: The PDGene database. PLoS genetics 8(3):e1002548.

Lister R, Mukamel EA, Nery JR, Urich M, Puddifoot CA, Johnson ND, Lucero J, Huang Y, Dwork AJ, Schultz MD, Yu M, Tonti-Filippini J, Heyn H, Hu S, Wu JC, Rao A, Esteller M, He C, Haghighi FG, Sejnowski TJ, Behrens MM, Ecker JR. 2013. Global epigenomic reconfiguration during mammalian brain development. Science 341(6146):1237905.

Lubin FD, Gupta S, Parrish RR, Grissom NM, Davis RL. 2011. Epigenetic mechanisms: critical contributors to long-term memory formation. The Neuroscientist : a review journal bringing neurobiology, neurology and psychiatry 17(6):616-632.

Massart R, Freyburger M, Suderman M, Paquet J, El Helou J, Belanger-Nelson E, Rachalski A, Koumar OC, Carrier J, Szyf M, Mongrain V. 2014. The genome-wide landscape of DNA methylation and hydroxymethylation in response to sleep deprivation impacts on synaptic plasticity genes. Translational psychiatry 4:e347.

Mellen M, Ayata P, Dewell S, Kriaucionis S, Heintz N. 2012. MeCP2 binds to 5hmC enriched within active genes and accessible chromatin in the nervous system. Cell 151(7):14171430.

Miller CA, Sweatt JD. 2006. Amnesia or retrieval deficit? Implications of a molecular approach to the question of reconsolidation. Learning \& memory 13(5):498-505.

Mina E, van Roon-Mom W, Hettne K, van Zwet E, Goeman J, Neri C, P ACtH, Mons B, Roos M. 2016. Common disease signatures from gene expression analysis in Huntington's disease human blood and brain. Orphanet journal of rare diseases 11(1):97.

Montano CM, Irizarry RA, Kaufmann WE, Talbot K, Gur RE, Feinberg AP, Taub MA. 2013. Measuring cell-type specific differential methylation in human brain tissue. Genome biology 14(8):R94. 
Nogales-Cadenas R, Carmona-Saez P, Vazquez M, Vicente C, Yang X, Tirado F, Carazo JM, Pascual-Montano A. 2009. GeneCodis: interpreting gene lists through enrichment analysis and integration of diverse biological information. Nucleic acids research 37(Web Server issue):W317-322.

Numata S, Ye T, Hyde TM, Guitart-Navarro X, Tao R, Wininger M, Colantuoni C, Weinberger DR, Kleinman JE, Lipska BK. 2012. DNA methylation signatures in development and aging of the human prefrontal cortex. American journal of human genetics 90(2):260-272.

Paez-Colasante X, Figueroa-Romero C, Sakowski SA, Goutman SA, Feldman EL. 2015. Amyotrophic lateral sclerosis: mechanisms and therapeutics in the epigenomic era. Nature reviews Neurology 11(5):266-279.

Paisan-Ruiz C, Jain S, Evans EW, Gilks WP, Simon J, van der Brug M, Lopez de Munain A, Aparicio S, Gil AM, Khan N, Johnson J, Martinez JR, Nicholl D, Carrera IM, Pena AS, de Silva R, Lees A, Marti-Masso JF, Perez-Tur J, Wood NW, Singleton AB. 2004. Cloning of the gene containing mutations that cause PARK8-linked Parkinson's disease. Neuron 44(4):595-600.

Quinlan AR, Hall IM. 2010. BEDTools: a flexible suite of utilities for comparing genomic features. Bioinformatics 26(6):841-842.

Sanchez-Mut JV, Aso E, Panayotis N, Lott I, Dierssen M, Rabano A, Urdinguio RG, Fernandez AF, Astudillo A, Martin-Subero JI, Balint B, Fraga MF, Gomez A, Gurnot C, Roux JC, Avila J, Hensch TK, Ferrer I, Esteller M. 2013. DNA methylation map of mouse and human brain identifies target genes in Alzheimer's disease. Brain : a journal of neurology 136(Pt 10):3018-3027.

Sanchez-Mut JV, Graff J. 2015. Epigenetic Alterations in Alzheimer's Disease. Frontiers in behavioral neuroscience 9:347.

Sanchez-Mut JV, Heyn H, Vidal E, Moran S, Sayols S, Delgado-Morales R, Schultz MD, Ansoleaga B, Garcia-Esparcia P, Pons-Espinal M, de Lagran MM, Dopazo J, Rabano A, Avila J, Dierssen M, Lott I, Ferrer I, Ecker JR, Esteller M. 2016. Human DNA methylomes of neurodegenerative diseases show common epigenomic patterns. Translational psychiatry 6:e718.

Sandoval J, Heyn H, Moran S, Serra-Musach J, Pujana MA, Bibikova M, Esteller M. 2011. Validation of a DNA methylation microarray for $450,000 \mathrm{CpG}$ sites in the human genome. Epigenetics 6(6):692-702.

Schrijver HM, Crusius JB, Uitdehaag BM, Garcia Gonzalez MA, Kostense PJ, Polman CH, Pena AS. 1999. Association of interleukin-1beta and interleukin-1 receptor antagonist genes with disease severity in MS. Neurology 52(3):595-599.

Sun L, Wang J, Yin X, Sun S, Zi C, Zhu G, Wu S, Bao W. 2016. Identification of a 5Methylcytosine Site that may Regulate C/EBPbeta Binding and Determine TissueSpecific Expression of the BPI Gene in Piglets. Scientific reports 6:28506.

Tabas-Madrid D, Nogales-Cadenas R, Pascual-Montano A. 2012. GeneCodis3: a non-redundant and modular enrichment analysis tool for functional genomics. Nucleic acids research 40(Web Server issue):W478-483.

Thomas PD, Kejariwal A, Campbell MJ, Mi H, Diemer K, Guo N, Ladunga I, Ulitsky-Lazareva B, Muruganujan A, Rabkin S, Vandergriff JA, Doremieux O. 2003. PANTHER: a browsable database of gene products organized by biological function, using curated protein family and subfamily classification. Nucleic acids research 31(1):334-341.

Valente EM, Abou-Sleiman PM, Caputo V, Muqit MM, Harvey K, Gispert S, Ali Z, Del Turco D, Bentivoglio AR, Healy DG, Albanese A, Nussbaum R, Gonzalez-Maldonado R, Deller T, Salvi S, Cortelli P, Gilks WP, Latchman DS, Harvey RJ, Dallapiccola B, Auburger G, Wood NW. 2004. Hereditary early-onset Parkinson's disease caused by mutations in PINK1. Science 304(5674):1158-1160.

Vinson C, Chatterjee R. 2012. CG methylation. Epigenomics 4(6):655-663. 
Whitfield DR, Vallortigara J, Alghamdi A, Hortobagyi T, Ballard C, Thomas AJ, O'Brien JT, Aarsland D, Francis PT. 2015. Depression and synaptic zinc regulation in Alzheimer disease, dementia with lewy bodies, and Parkinson disease dementia. The American journal of geriatric psychiatry : official journal of the American Association for Geriatric Psychiatry 23(2):141-148.

Wood JN, Grafman J. 2003. Human prefrontal cortex: processing and representational perspectives. Nature reviews Neuroscience 4(2):139-147.

Xin Y, Chanrion B, Liu MM, Galfalvy H, Costa R, Ilievski B, Rosoklija G, Arango V, Dwork AJ, Mann JJ, Tycko B, Haghighi F. 2010. Genome-wide divergence of DNA methylation marks in cerebral and cerebellar cortices. PloS one 5(6):e11357.

Xu H, Handoko L, Wei X, Ye C, Sheng J, Wei CL, Lin F, Sung WK. 2010. A signal-noise model for significance analysis of ChIP-seq with negative control. Bioinformatics 26(9):11991204.

Zemach A, McDaniel IE, Silva P, Zilberman D. 2010. Genome-wide evolutionary analysis of eukaryotic DNA methylation. Science 328(5980):916-919.

Zhu J, Adli M, Zou JY, Verstappen G, Coyne M, Zhang X, Durham T, Miri M, Deshpande V, De Jager PL, Bennett DA, Houmard JA, Muoio DM, Onder TT, Camahort R, Cowan CA, Meissner A, Epstein CB, Shoresh N, Bernstein BE. 2013. Genome-wide chromatin state transitions associated with developmental and environmental cues. Cell 152(3):642654.

Ziller MJ, Muller F, Liao J, Zhang Y, Gu H, Bock C, Boyle P, Epstein CB, Bernstein BE, Lengauer T, Gnirke A, Meissner A. 2011. Genomic distribution and inter-sample variation of non-

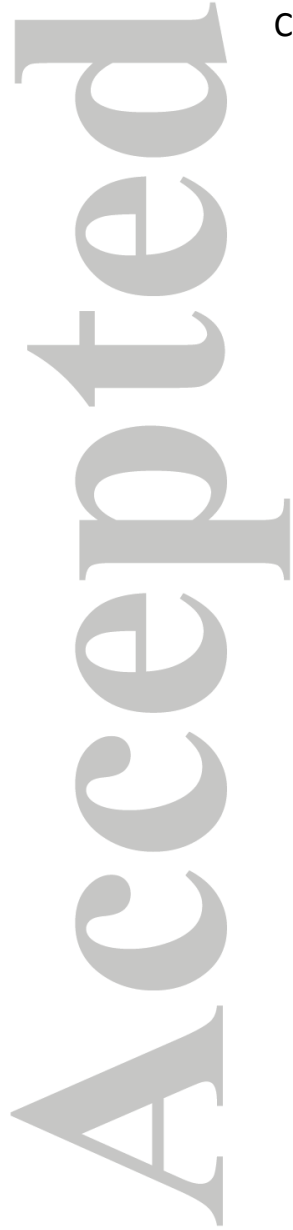
CpG methylation across human cell types. PLoS genetics 7(12):e1002389. 
Figure 1. WGBS of Grey (G145) and White matter (W145) DMRs. (A) Circos representation of DMR between Grey and White matter samples. Outer circle represents average levels for all of DMRs in $50 \mathrm{Mbp}$-wide windows. Inner circle represents average levels for all of DMRs in 200 Kbp-wide windows. Bars indicate the magnitude of the difference between the G145 and the W145 samples for each window (color scale). (B) DMR distribution among different genomic regions, left. DMR overlapping with different histone marks, right. Observed DMRs refers to total number of DMRs obtained. Expected DMRs refers to expected DMR distribution randomly permuting their locations among the genome. (C) DNA methylation and gene expression correlation. DNA promoter methylation and gene expression correlation for each of samples analyzed (Grey matter $\mathrm{R}=-0.49$; White matter $\mathrm{R}=-0.47$; Pearson correlations, $\mathrm{p}$-val $<0.001$ ).

Figure 2. Heatmap clustering of $450 \mathrm{~K}$ data between grey and white matter samples. CpGs covering WGBS DMRs were selected to cluster five grey and five white samples. Red and green colors indicate high and low levels of DNA methylation respectively.

Figure 3. DMR examples of relevant genes. (A) DMRs overlapping promoters of cell type markers. (B) DMRs overlapping promoters of disease-associated genes. Smoothing values for grey and white matter are represented by red and blue lines respectively. Dots represent single sequencing reads, and light red and blue areas represent the confidence interval of the data.

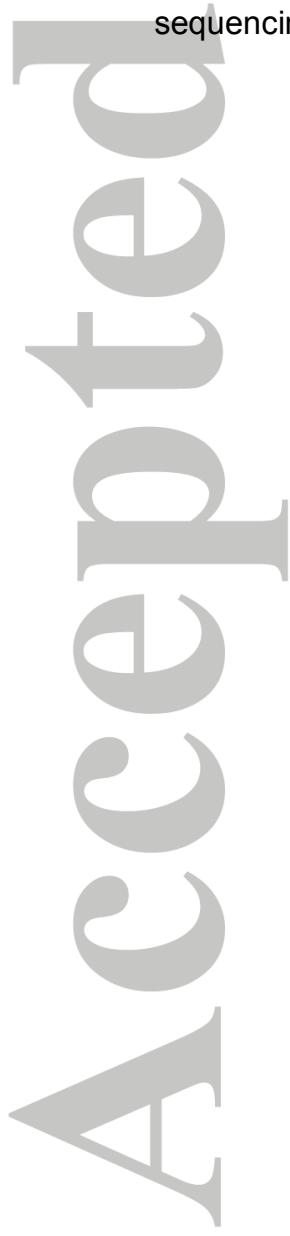


A

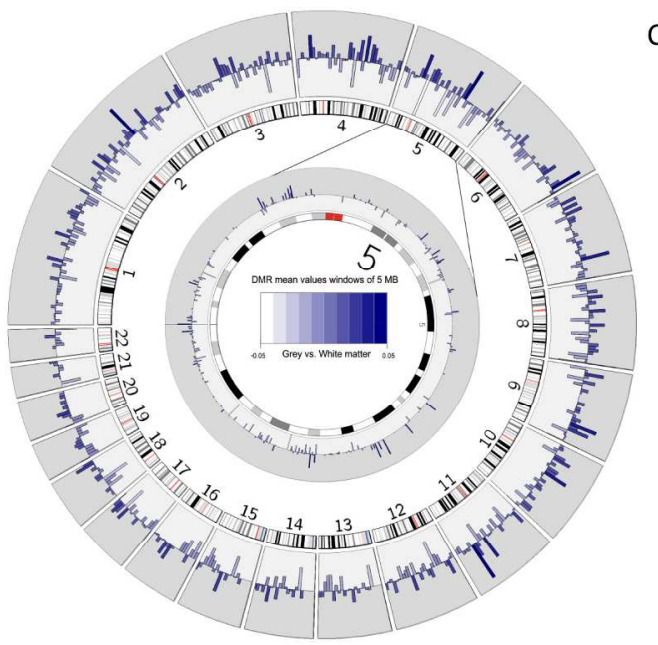

C

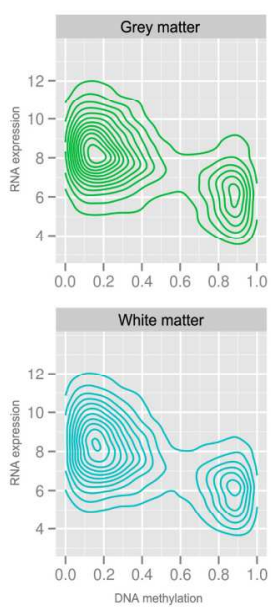

Figure 1

B

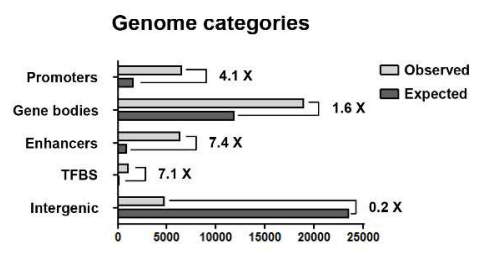

HIstone marks

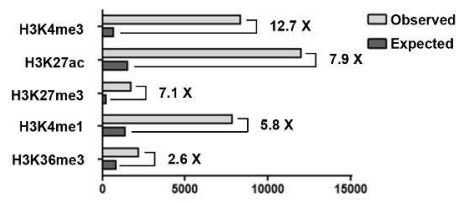

Figure 1. WGBS of Grey (G145) and White matter (W145) DMRs. (A) Circos representation of DMR between Grey and White matter samples. Outer circle represents average levels for all of DMRs in 50 Mbp-wide windows. Inner circle represents average levels for all of DMRs in $200 \mathrm{Kbp}$-wide windows. Bars indicate the magnitude of the difference between the G145 and the W145 samples for each window (color scale). (B) DMR distribution among different genomic regions, left. DMR overlapping with different histone marks, right. Observed DMRs refers to total number of DMRs obtained. Expected DMRs refers to expected DMR distribution randomly permuting their locations among the genome. (C) DNA methylation and gene expression correlation. DNA promoter methylation and gene expression correlation for each of samples analyzed (Grey matter $\mathrm{R}=-0.49$; White matter $\mathrm{R}=-0.47$; Pearson correlations, $\mathrm{p}-\mathrm{val}<0.001$ ).

$257 \times 190 \mathrm{~mm}(300 \times 300$ DPI $)$

This article is protected by copyright. All rights reserved. 
Figure 2

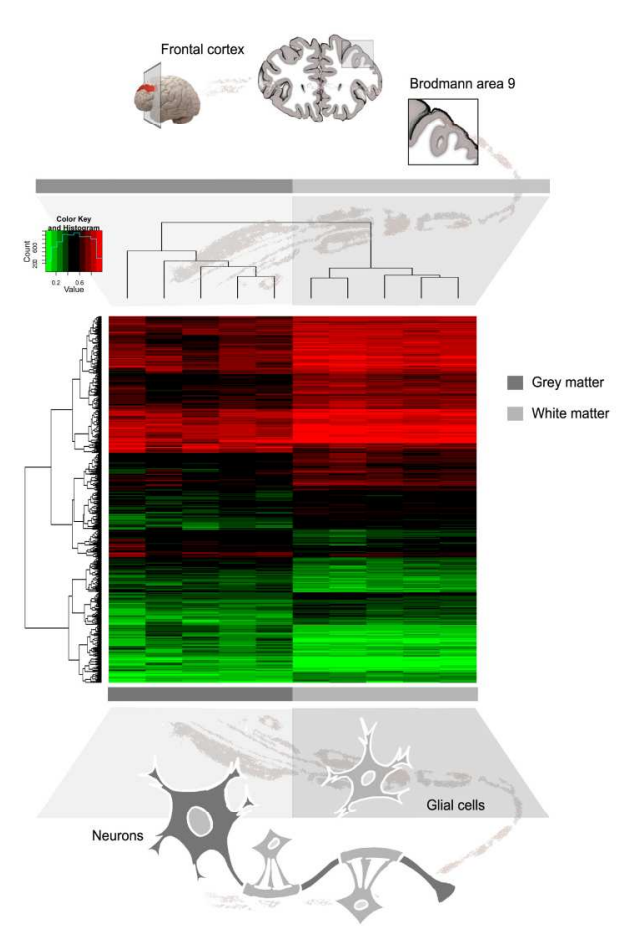

Figure 2. Heatmap clustering of $450 \mathrm{~K}$ data between grey and white matter samples. CpGs covering WGBS DMRs were selected to cluster five grey and five white samples. Red and green colors indicate high and low levels of DNA methylation respectively.

$257 \times 190 \mathrm{~mm}(300 \times 300$ DPI $)$ 
Figure 3

A
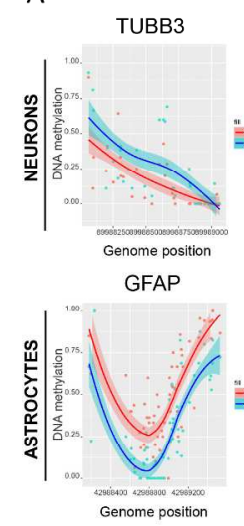

ENO2

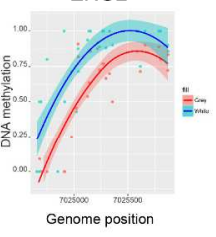

MAG

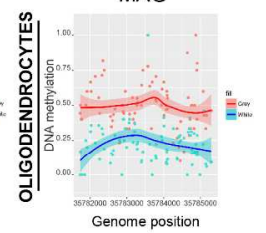

B

B CLU
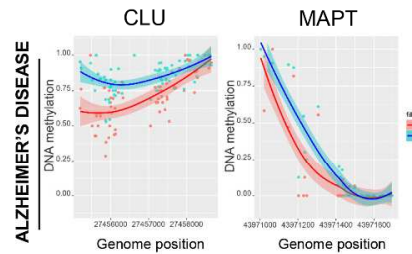

PINK1
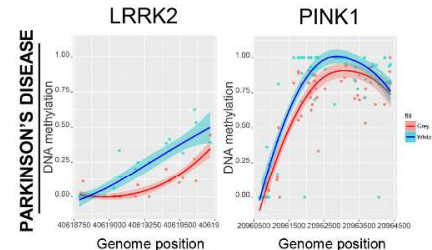

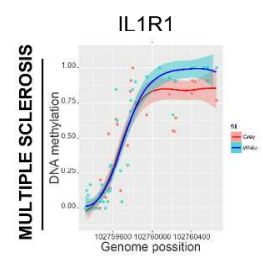

TNFRSF1A

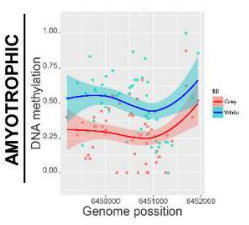

Figure 3. DMR examples of relevant genes. (A) DMRs overlapping promoters of cell type markers. (B) DMRs overlapping promoters of disease-associated genes. Smoothing values for grey and white matter are represented by red and blue lines respectively. Dots represent single sequencing reads, and light red and blue areas represent the confidence interval of the data.

$$
258 \times 190 \mathrm{~mm}(300 \times 300 \mathrm{DPI})
$$

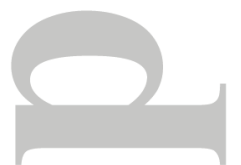


Table 1. Panther terms enrichments on genes differentially methylated between grey and white matter.

\begin{tabular}{|c|c|c|}
\hline Panther terms & Genes & Hyp* \\
\hline Wnt signaling pathway & 136 genes & $4.41 \mathrm{E}-25$ \\
\hline Endothelin signaling pathway & 50 genes & $7.42 \mathrm{E}-18$ \\
\hline Angiogenesis & 79 genes & $8.82 \mathrm{E}-17$ \\
\hline EGF receptor signaling pathway & 64 genes & $4.41 \mathrm{E}-16$ \\
\hline PDGF signaling pathway & 68 genes & $1.25 \mathrm{E}-15$ \\
\hline Integrin signalling pathway & 78 genes & $1.30 \mathrm{E}-15$ \\
\hline Heterotrimeric G-protein signaling pathway-Gq alpha and Go alpha mediated pathway & 61 genes & $1.35 \mathrm{E}-15$ \\
\hline Inflammation mediated by chemokine and cytokine signaling pathway & 89 genes & $1.82 \mathrm{E}-14$ \\
\hline Heterotrimeric G-protein signaling pathway-Gi alpha and Gs alpha mediated pathway & 71 genes & $4.92 \mathrm{E}-13$ \\
\hline FGF signaling pathway & 57 genes & $6.68 \mathrm{E}-13$ \\
\hline Apoptosis signaling pathway & 56 genes & $8.82 \mathrm{E}-13$ \\
\hline Alzheimer disease-amyloid secretase pathway & 41 genes & $9.12 \mathrm{E}-13$ \\
\hline p53 pathway & 45 genes & $2.19 \mathrm{E}-12$ \\
\hline Muscarinic acetylcholine receptor 1 and 3 signaling pathway & 36 genes & 1.14E-11 \\
\hline Oxytocin receptor mediated signaling pathway & 35 genes & $1.59 \mathrm{E}-11$ \\
\hline Ras Pathway & 40 genes & $3.06 \mathrm{E}-11$ \\
\hline Histamine $\mathrm{H} 1$ receptor mediated signaling pathway & 29 genes & $5.28 \mathrm{E}-11$ \\
\hline Thyrotropin-releasing hormone receptor signaling pathway & 35 genes & $5.96 \mathrm{E}-11$ \\
\hline Huntington disease & 58 genes & $2.04 \mathrm{E}-10$ \\
\hline TGF-beta signaling pathway & 46 genes & $4.04 \mathrm{E}-10$ \\
\hline Cadherin signaling pathway & 60 genes & 3.01E-09 \\
\hline VEGF signaling pathway & 33 genes & 3.31E-09 \\
\hline Alzheimer disease-presenilin pathway & 53 genes & 3.57E-09 \\
\hline 5HT2 type receptor mediated signaling pathway & 35 genes & $4.01 \mathrm{E}-09$ \\
\hline Notch signaling pathway & 24 genes & $7.24 \mathrm{E}-09$ \\
\hline GABA-B receptor II signaling & 24 genes & 1.61E-08 \\
\hline Metabotropic glutamate receptor group III pathway & 33 genes & $7.70 \mathrm{E}-08$ \\
\hline Beta2 adrenergic receptor signaling pathway & 25 genes & $8.75 \mathrm{E}-08$ \\
\hline Beta1 adrenergic receptor signaling pathway & 25 genes & $8.75 \mathrm{E}-08$ \\
\hline Parkinson disease & 40 genes & 9.87E-08 \\
\hline PI3 kinase pathway & 28 genes & 1.37E-07 \\
\hline Muscarinic acetylcholine receptor 2 and 4 signaling pathway & 29 genes & 4.20E-07 \\
\hline Alpha adrenergic receptor signaling pathway & 16 genes & $4.94 \mathrm{E}-07$ \\
\hline Metabotropic glutamate receptor group II pathway & 25 genes & $4.95 \mathrm{E}-07$ \\
\hline B cell activation & 29 genes & $1.64 \mathrm{E}-06$ \\
\hline Synaptic vesicle trafficking & 17 genes & $2.01 \mathrm{E}-06$ \\
\hline Metabotropic glutamate receptor group I pathway & 16 genes & $2.88 \mathrm{E}-06$ \\
\hline Oxidative stress response & 25 genes & $5.88 \mathrm{E}-06$ \\
\hline Ionotropic glutamate receptor pathway & 23 genes & $5.90 \mathrm{E}-06$ \\
\hline p53 pathway feedback loops 2 & 24 genes & $5.96 \mathrm{E}-06$ \\
\hline Histamine $\mathrm{H} 2$ receptor mediated signaling pathway & 15 genes & $8.78 \mathrm{E}-06$ \\
\hline Interferon-gamma signaling pathway & 17 genes & $1.55 \mathrm{E}-05$ \\
\hline Nicotinic acetylcholine receptor signaling pathway & 36 genes & $2.73 \mathrm{E}-05$ \\
\hline Cytoskeletal regulation by Rho GTPase & 30 genes & $2.91 \mathrm{E}-05$ \\
\hline Axon guidance mediated by semaphorins & 13 genes & 4.00E-05 \\
\hline$T$ cell activation & 32 genes & $4.26 \mathrm{E}-05$ \\
\hline Circadian clock system & 8 genes & $4.89 \mathrm{E}-05$ \\
\hline Toll receptor signaling pathway & 22 genes & $5.00 \mathrm{E}-05$ \\
\hline Hypoxia response via HIF activation & 15 genes & $6.28 \mathrm{E}-05$ \\
\hline FAS signaling pathway & 18 genes & $7.98 \mathrm{E}-05$ \\
\hline
\end{tabular}




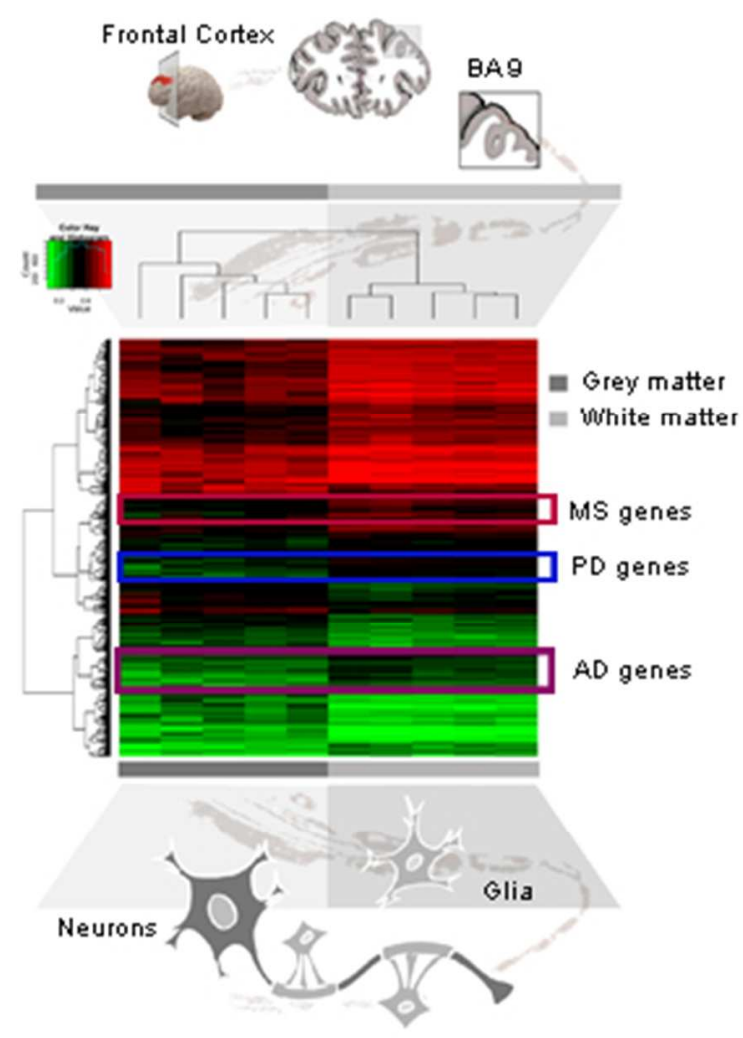

Using whole genome bisulfite sequencing and highthroughput arrays, the authors characterize the DNA - methylation patterns of white and grey matter in the prefrontal cortex. Genes differentially methylated were found to be enriched in molecular pathways highly relevant for neuron/glia function and neurodegenerative diseases.

$105 \times 141 \mathrm{~mm}(72 \times 72 \mathrm{DPI})$ 
Using whole genome bisulfite sequencing and highthroughput arrays, the authors characterize the DNA methylation patterns of white and grey matter in the prefrontal cortex. Genes differentially methylated were found to be enriched in molecular pathways highly relevant for neuron/glia function and neurodegenerative diseases.
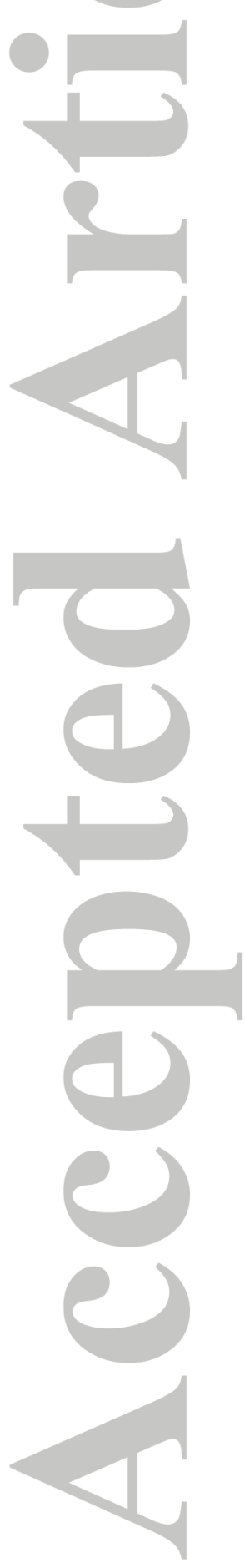